\title{
CCR10 and its ligands in regulation of epithelial immunity and diseases
}

\author{
Na Xiong ${ }^{\bowtie}$, Yaoyao Fu, Shaomin Hu, Mingcan Xia, Jie Yang \\ Center for Molecular Immunology and Infectious Diseases and Department of Veterinary and Biomedical Sciences, \\ The Pennsylvania State University, PA 16802, USA \\ $\square$ Correspondence: nux1@psu.edu \\ Received March 29, 2012 Accepted April 11, 2012
}

\begin{abstract}
Epithelial tissues covering the external and internal surface of a body are constantly under physical, chemical or biological assaults. To protect the epithelial tissues and maintain their homeostasis, multiple layers of immune defense mechanisms are required. Besides the epithelial tissue-resident immune cells that provide the first line of defense, circulating immune cells are also recruited into the local tissues in response to challenges. Chemokines and chemokine receptors regulate tissue-specific migration, maintenance and functions of immune cells. Among them, chemokine receptor CCR10 and its ligands chemokines CCL27 and CCL28 are uniquely involved in the epithelial immunity. CCL27 is expressed predominantly in the skin by keratinocytes while CCL28 is expressed by epithelial cells of various mucosal tissues. CCR10 is expressed by various subsets of innate-like $T$ cells that are programmed to localize to the skin during their developmental processes in the thymus. Circulating $T$ cells might be imprinted by skin-associated antigen-presenting cells to express CCR10 for their recruitment to the skin during the local immune response. On the other hand, IgA antibody-producing B cells generated in mucosa-associated lymphoid tissues express CCR10 for their migration and maintenance at mucosal sites. Increasing evidence also found that CCR10/ligands are involved in regulation of other immune cells in epithelial immunity and are frequently exploited by epithelium-localizing or -originated cancer cells for their survival, proliferation and evasion from immune surveillance. Herein, we review current knowledge on roles of CCR10/ligands in regulation of epithelial immunity and diseases and speculate on re-
\end{abstract}

lated important questions worth further investigation.

KEYWORDS CCR10, epithelial immunity, epithelial diseases

\section{INTRODUCTION}

Chemokine receptors are a group of membrane proteins of about 350 amino acids in size and belong to the seven-transmembrane, G protein-coupled protein superfamily. Nineteen chemokine receptors have been identified in mammals up to date (Charo and Ransohoff, 2006). Based on types of chemokines (a group of secreted proteins with approximately 80 amino acids in length) they bind to, chemokine receptors could be divided into four subfamilies. The CC chemokine receptors consist of ten members (CCR1-10) that are receptors for ligands of the CC chemokine subfamily (containing at least 27 members, CCL1-28). Seven members of the CXC chemokine receptor subfamily (CXCR1-7) are receptors for 17 CXC chemokines (CXCL1-17). The only member of the CX3C chemokine receptor subfamily, CX3CR1, is the receptor for CX3C chemokine ligand 1 (CX3CL1) and the XC chemokine receptor XCR1 is the receptor for the XC chemokine ligands 1 and 2 (XCL1 and XCL2). Chemokine receptors and ligands are expressed by diverse types of cells and play critical roles in embryogenesis, tissue repair and immune responses. Chemokine receptors expressed on cells direct their migration along guidance cues provided by their respective ligands, a process called chemotaxis. The chemokine receptor-transduced signals are also involved in cellular survival, proliferation, activation and other functions.

CCR10 is the last member of the CC chemokine receptor subfamily. The gene coding for CCR10 was first reported in 
1994 under the name GPR2 (G-protein coupled receptor 2) that shows high homology to known chemokine receptors (Marchese et al., 1994). However, GPR2 as a chemokine receptor was not established until it was found as a receptor for CCL27 (also called ESkine, ALP, ILC or CTACK), a chemokine expressed predominantly in the skin (Morales et al., 1999; Homey et al., 2000; Jarmin et al., 2000). As a result, the name GPR2 was replaced with CCR10. Soon after, CCL28 (also called MEC, CCK1 or SCYA28), a chemokine predominantly expressed in mucosal sites, was identified as another ligand for CCR10 (Pan et al., 2000; Wang et al., 2000). CCL28 shares higher homology to CCL27 than to any other chemokine.

In this article, we review roles of CCR10 and its ligands CCL27 and CCL28 in regulation of development and functions of various immune cells in epithelial tissues, particularly the skin and intestine. In addition, we also review involvement of CCR10/ligands in growth and metastasis of tumors, which could alter the expression of CCR10 and its ligands to evade the immune surveillance and promote their proliferation and survival.

\section{EXPRESSION PROFILES OF CCR10 AND ITS LIGANDS SUGGEST THEIR ROLES PREDOMINANTLY IN REGULATION OF IMMUNE RESPONSES IN EPITHELIAL TISSUES}

CCL27 and CCL28 have relatively restricted expression patterns in normal physiological conditions. While transcripts of CCL27 are found in multiple tissues, it is predominantly expressed in the skin by keratinocytes (Morales et al., 1999; Homey et al., 2000). On the other hand, CCL28 is highly expressed by epithelial cells of mucosal tissues, such as intestines, reproductive tracts, lungs, stomach, lactating mammary glands and salivary glands (Pan et al., 2000; Wang et al., 2000; Hieshima et al., 2003).

Based on the transcript analysis, CCR10 has been reportedly expressed by cells of various types in the skin, including $\mathrm{T}$ cells, Langerhans cells, melanocytes and dermal endothelial cells (Homey et al., 2000; Jarmin et al., 2000). The skin-homing $\mathrm{CLA}^{+}$(cutaneous lymphocyte-associated antigen) $T$ cells of human blood, dermal microvascular endothelial cells and fibroblasts reportedly expressed CCR10 proteins on their cell surface (Homey et al., 2002). However, expression of CCR10 proteins on some of these cell types, such as Langerhans cells, has not been confirmed. In blood of humans, the CCR $10^{+} \mathrm{T}$ cells account for a small percentage of total circulating $\mathrm{T}$ cells. The circulating CCR $10^{+} \mathrm{T}$ cells express markers associated with memory/activation such as CD44. Many of them co-express migration or adhesion molecules associated with the skin-homing, such as CLA, suggesting that the circulating $\mathrm{CCR} 10^{+}$cells might represent a unique pre-activated, memory-like $T$ cell population with skin-homing properties or originating in the skin (Soler et al.,
2003). Recently, several studies reported that the CCR $10^{+}$ $\mathrm{CD}^{+} \mathrm{T}$ cells isolated from human blood are enriched with IL-22-producing cells (Duhen et al., 2009; Trifari et al., 2009). This specific IL-22-producing population is different from the previously described IL-17-producing $\mathrm{CD}^{+}{ }^{+} \mathrm{T}$ helper (Th17) cells in that the former produces IL-22 but not IL-17 while the Th17 cells could produce both IL-17 and IL-22. Based on this, the IL-22-producing $\mathrm{CD} 4^{+}$cells are named Th22 cells. The Th22 cells also preferentially express CCR6 and could be found at high percentages in the inflammatory skin (Eyerich et al., 2009).

Another major immune cell population that expresses CCR10 is immunoglobulin A (IgA) antibody-secreting plasma cells (IgA-ASC) (Kunkel et al., 2003). IgA is the most dominant form of antibodies generated in mucosa tissues, such as the intestine, lung, reproductive tract, lactating mammary glands and nasal cavity (Corthésy, 2007; Mora and von Andrian, 2008). IgA antibodies are produced by IgA-ASC localized in local mucosal tissues and secreted into the lumen or cavity of the mucosal tissues where they play an important role in maintaining homeostasis of the tissues and protecting against pathogens and toxins (Cerutti and Rescigno, 2008). The majority of IgA-producing plasma cells differentiate from naïve $B$ cells in mucosa-associated lymphoid tissues (MALT) such as the intestinal Peyer's patches in response to the stimulation of antigens in the local tissues (Suzuki and Fagarasan, 2009). After their generation in MALT, the immature $\operatorname{lgA}^{+}$plasmablasts migrate into effector sites such as the intestinal lamina propria, where they further differentiate into mature IgA-ASC. CCR10 starts to be upregulated on the $\lg \mathrm{A}^{+}$ plasmablasts and remains expressed on IgA-ASC, suggesting its role, through interaction with its mucosal ligand CCL28, in migration and maintenance of the $\operatorname{lgA}^{+}$cells in mucosal tissues (Pan et al., 2000; Kunkel et al., 2003; Lazarus et al., 2003). The vast majority of the blood $\operatorname{lgA}^{+}$plasma cells in humans express CCR10, consistent with the notion that they originate from mucosal responses (Mei et al., 2009).

CCR10 is also expressed on several subsets of developing thymic $T$ cells, particularly on those known to have a preference for epithelial locations, such as $\gamma \delta T$ and NK T cells (Jin et al., 2010b). In mice, fetal thymic $V_{Y} 3^{+} y \delta T$ cells, the progenitor cells for epidermis-resident skin intraepithelial $T$ cells (sIELs, also called dendritic epidermal $T$ cells or DETC), express CCR10 (Xiong et al., 2004). Using a strain of CCR10-knockout/EGFP-knockin (also called CCR10knockout mice in this review for simplicity) mice in which the coding region of enhanced green fluorescent protein (EGFP) replaces the CCR10 coding region to serve as a reporter for the endogenous CCR10 expression (Jin et al., 2010b), we confirmed that CCR10 is expressed on the positively-selected $\mathrm{CD} 122^{+} \mathrm{V}_{\mathrm{Y}} 3^{+}$fetal thymic sIEL precursor cells. In addition, significant percentages of $\mathrm{V}_{\gamma} 3^{-}$fetal thymic $ү \delta \mathrm{T}$ cells and adult thymic $\gamma \delta \mathrm{T}$ cells also express CCR10 (Jin et al., 2010b). However, they express other homing 
molecules differently than the fetal thymic $\mathrm{V}_{\mathrm{\gamma}} 3^{+} \mathrm{y} \delta \mathrm{T}$ cells. In addition, $10 \%-20 \%$ of $\mathrm{NK} 1.1^{+}$a $\mathrm{T}$ cells express CCR 10 . In contrast, nearly no conventional thymic $\mathrm{CD}^{+}{ }^{+}$or $\mathrm{CD}^{+} \alpha \beta \mathrm{T}$ cells express CCR10 (Jin et al., 2010b).

\section{ROLES OF CCR10/LIGANDS IN REGULATION OF T CELL RESPONSE IN THE SKIN}

Abundant evidence shows that CCR10 and its ligands are involved in the skin inflammation by regulating the $T$ cell infiltration and/or maintenance. In skin lesions of acute or chronic atopic dermatitis or psoriatic patients, expression of CCL27 by epidermal keratinocytes was upregulated and most skin-infiltrating lymphocytes express CCR10 (Homey et al., 2002). Correlating with this, increased levels of CCL27 were detected in sera of patients with various skin inflammatory diseases, including diffuse or limited cutaneous systemic sclerosis, atopic dermatitis, and psoriasis vulgaris (Kakinuma et al., 2003; Hijnen et al., 2004; Hon et al., 2004; Hayakawa et al., 2005; Song et al., 2006). In an early study using Blab/c mouse models, the antibody neutralization of CCL27 impaired the $T$ cell recruitment into the inflamed skin induced by the tropic treatment with the allergen DNFB (2,4-dinitro1-fluorobenzene), suggesting that the CCL27/CCR10 axis has a pivotal role in $\mathrm{T}$ cell-mediated skin inflammation (Homey et al., 2002). However, another study found that only a small percentage $(\sim 10 \%)$ of skin-infiltrating $T$ lymphocytes in the allergen and bacterial chancroid-induced skin lesions of human subjects express CCR 10 while most of them express CCR4, suggesting that CCR10 is unlikely critical for cutaneous homing of most T cells (Soler et al., 2003). Supporting this, in an experiment in which direct migration of transferred $\mathrm{CD}^{+} \mathrm{T}$ cells into the inflamed skin of C57BL/6 mice was assessed, the anti-CCL27 antibody treatment did not affect the recruitment of wild type $\mathrm{CD}^{+}$donor T cells (Reiss et al., 2001). In contrast, the anti-CCL27 antibody blockage reduced recruitment of CCR4-deficient $T$ cells into the skin. Since the CCR4-deficient T cells did not have any defect in migration into the skin themselves, these findings indicate that CCL27 (likely through CCR10) and CCR4 function redundantly in the $T$ cell recruitment into the inflamed skin.

The discrepancy in functional importance of the CCL27/CCR10 axis among various reports could be due to the different models used since the upregulation of CCL27 and other chemokines could be regulated differently in those models. In fact, while the upregulation of CCL27 and CCL17, a ligand for CCR4, was demonstrated in allergic dermatitis (Homey et al., 2002; Moed et al., 2004; Kanda et al., 2005; Riis et al., 2011a), one recent report found a markedly decreased CCL27 expression in psoriatic lesions compared with non-lesional psoriatic skin and there was only a minor CCL17 mRNA increase in lesional psoriatic skin (Riis et al., 2011a). In addition, the expression of CCR4 was found on CCR $10^{+}$lymphocytes in atopic dermatitis skin but not in psoriasis skin (Vestergaard et al., 2003). Therefore, there might be differential involvement of CCR10 and other chemokine receptors in different skin inflammatory conditions. Consistent with this, mice expressing transgenic CCL27 in the skin show enhanced chronic contact hypersensitivity induced by FITC that preferentially induces Th2 (T helper cell type 2) response but not by oxazolone that preferentially induces the Th1 response (Kagami et al., 2008). In addition, in the keratin-14 promoter-driven IL-4 transgenic mouse model of atopic dermatitis that is characterized by the early upregulation of Th2 cytokines and late surge of Th1 cytokines, subcutaneous injection of anti-CCL27 antibodies at the early stage reduced inflammation (Chen et al., 2006). However, in a systematic study of roles of ligands for CCR10 vs CCR4 in mouse models of DNFB-(preferentially Tc1 mediated), oxazolone-(Th1), or trimellitic acid anhydride-(Th2) induced contact hypersensitivity, combination antibody therapy to ligands of both CCR4 and CCR10 resulted in a greater reduction of the inflammatory response than the treatments targeting either one, supporting redundant roles of the two receptors (Mirshahpanah et al., 2008). Moreover, co-transferred CCR10-sufficent and CCR10-deficient $\mathrm{CD}^{+}{ }^{+} \mathrm{T}$ cells migrate at similar efficiencies into the DNFB-treated skin of recipient mice, providing direct evidence that CCR10 is not critical for the $T$ cell infiltration into the skin during the local inflammation (Tubo et al., 2011). Therefore, functional importance and mechanisms of CCR10 in the skin T cell response are still not fully understood.

CCR10 could be expressed by other immune cells for their migration and location in the skin. One recent report found that blood-originated plasmacytoid dendritic (pDCs) cells might be instructed to upregulate CCR 10 and/or CCR6 when activated in lymphoid tissues draining inflamed epithelia, allowing their homing into the inflamed epithelia such as mucosa and skin (Sisirak et al., 2011). However, it was not tested what is function of CCR10 on these cells.

\section{ROLES OF CCR10/LIGANDS IN REGULATION OF INTESTINAL IGA RESPONSE AT MUCOSAL SITES}

Considering that all $\lg \mathrm{A}^{+}$plasma cells express $\mathrm{CCR} 10$, it has long been suggested that CCR10 is involved in the IgA responses in mucosal tissues. Consistent with this notion, intestinal, but not systemic, immunization in human subjects efficiently generated $\mathrm{CCR} 0^{+}$antigen-specific $\mathrm{IgA}^{+}$cells (Sundström et al., 2008). Intranasal or intravaginal, but not subcutaneous, immunization generates specific IgA-ASC homing to the uteri of vaccinated mice (Cha et al., 2011). IgA-ASC in the uteri of vaccinated mice were reduced drastically by the treatment with neutralizing anti-CCL28 antibodies, indicating a critical role of CCL28 in mediating recruitment of these cells into the uterus. Interestingly, systemic immunization together with CCL27 or CCL28 as adjuvants elicits greater antigen-specific $\lg \mathrm{A}$ antibody secretion into the 
mucosa such as bronchoalveolar lavage fluids and feces (Kraynyak et al., 2010; Rainone et al., 2011), suggesting the usefulness of CCL27 and CCL28 in enhancing mucosal IgA response of vaccines. CCR10/ligands are also important in controlling the recruitment of IgA-ASC in lactating mammary glands and therefore the $\lg A$ antibody transfer to the neonate (Wilson and Butcher, 2004; Morteau et al., 2008).

In spite of the abundant evidence implicating CCR10 in the IgA response at multiple mucosal sites, its role in the intestinal IgA response is not clear until recently. One earlier study reported that the treatment with neutralizing anti-CCL28 antibodies impaired intestinal IgA production in response to oral immunization of cholera toxin in a mouse model (Hieshima et al., 2004). However, the anti-CCL28 antibody treatment did not have any effect on the IgA response to intestinal rotavirus infection (Feng et al., 2006). On the other hand, the antibody blockage of CCL28 in CCR9-knockout mice reduced fecal production of the rotavirus-specific IgA antibodies compared to either anti-CCL28 blockage or CCR9 knockout alone, suggesting that CCR9 and CCR10 function redundantly in regulating the intestinal IgA response. Furthermore, there was no defect in the homeostatic IgA production in intestines of CCR10-knockout mice (Morteau et al., 2008). These studies suggest that CCR10/ligands are not critically required for normal levels of IgA responses to either commensal bacteria or pathogen infection, likely due to compensatory mechanisms. However, the CCR10-deficient $\lg \mathrm{A}^{+}$cells are defective in migration towards CCL28 in an in vitro migration assay, suggesting that no other chemokine receptors could substitute for absence of CCR10 in migration towards CCL28 attraction. In addition, expression patterns of CCR9 and CCR10 and their ligands in intestines were significantly different. Particularly, while CCR10 remains expressed on all mature IgA-ASC in the intestine, CCR9 is downregulated/non-functional on them (Bowman et al., 2002; Kunkel et al., 2003; Pabst et al., 2004; Mei et al., 2009). In addition, CCL28 is expressed in both small and large intestines while the ligand for CCR9, CCL25, is predominantly expressed in small intestines (Pan et al., 2000; Wang et al., 2000; Bowman et al., 2002; Kunkel et al., 2003; Pabst et al., 2004; Mei et al., 2009).

Using an in vivo migration assay, we found that CCR10-deficient IgA ${ }^{+}$plasma cells are defective in migration into both small and large intestines (Hu et al., 2011). Therefore, the apparently normal IgA level in CCR10-knockout mice is due to a compensation mechanism other than functional redundancy of any other homing receptor with CCR 10. The CCR10-knockout mice have enhanced generation of $\lg \mathrm{A}^{+}$ cells in increased numbers of isolated lymphoid follicles (ILF) in intestines (Hu et al., 2011). ILF are the dynamic B cell-rich follicles known to support generation of $\lg \mathrm{A}^{+}$cells in response to stimulation from commensal bacteria (Lorenz et al., 2003; McDonald and Newberry, 2007). The increased generation of IgA-ASC in ILFs likely compensates for the defec- tive intestinal migration and/or maintenance of the CCR10-deficient IgA ${ }^{+}$cells to provide the sufficient IgA production. However, the compensatorily generated $\lg \mathrm{A}^{+}$cells have reduced hypermutation in immunoglobulin heavy chains of IgA antibodies, indicating that they are qualitatively different from those of wild type mice and might have the impaired capacity to control intestinal homeostasis of commensal bacteria (Hu et al., 2011). Supporting this, the CCR10knockout mice have increased commensal bacteria in the colon.

CCR10-knockout mice could also mount an efficient IgA response to pathogenic bacteria citrobacter infection although the response is slightly slower than that in wild type mice. However, the long-term maintenance of citrobacter-specific IgA-producing plasma cells is profoundly impaired in CCR10-knockout mice (Hu et al., 2011). In addition, there was almost no memory $\lg A$ response to citrobacter re-infection in CCR10-knockout mice. While mechanisms underlying the impaired intestinal IgA memory response are not fully understood, impaired maintenance of a subset of $\mathrm{CCR} 10^{+}$citrobacter-specific $\lg \mathrm{A}^{+}$memory $\mathrm{B}$ cells in intestines of CCR10-knockout mice might be involved. These studies establish that CCR10 plays an important role in intestinal migration and/or maintenance of the IgA-producing plasma and memory B cells.

\section{INVOLVEMENT OF CCR10/LIGANDS IN REGULA- TION OF IMMUNE CELL REACTION OTHER THAN IGA RESPONSE AT MUCOSAL SITES}

CCR10/ligands are also involved in regulation of immune cells other than the IgA-ASC at mucosal sites. In the lung, levels of CCL28 expression are increased in mice sensitized and rechallenged with cockroach antigen, which induces pulmonary inflammation (John et al., 2005). The airway inflammation was reduced 24 hours after the treatment with anti-CCL28 sera. The reduced inflammation was associated with reduced peribronchial eosinophilia, suggesting that CCL28 plays an important role in mediating recruitment of eosinophils to peribronchial regions of the lung in this model. Interestingly, the CCL28-mediated eosinophil recruitment is not dependent on CCR10. Instead, the eosinophil-expressed CCR3, another chemokine receptor for CCL28, might be important. The upregulation of CCL28 in epithelia of inflamed lungs was also found in the airway inflammation model induced by challenge with ovalbumin (English et al., 2006). Different from the first model, the inflammation was accompanied by increased detection of cells expressing CCR10 in airways (English et al., 2006). In a mouse model of Sendai virus-induced chronic lung disease, cross-linking IgE receptors on pulmonary dendritic cells resulted in the increased production of CCL28, which might be involved in recruitment of IL-13-producing $\mathrm{CD}^{+}{ }^{+} \mathrm{T}$ cells to the lung (Grayson et al., 2007). Antibody blockade of CCL28 inhibits the virus-induced 
mucous cell metaplasia in the lung, suggesting CCL28 as an important molecule linking the antiviral response to an allergic Th2 response. It has also been suggested that the CCL28-induced recruitment of $\operatorname{lgE}^{+}$antibody-secreting cells contributes to the airway inflammation based on a human cellular line study (Scanlon et al., 2011) but whether this is the case in vivo is not clear. The role of CCR10 in this process is not clear either.

\section{ROLES OF CCR10/LIGANDS IN DEVELOPMENT OF SKIN-RESIDENT Yठ T CELLS}

In mice, the fetal thymus-originated $\mathrm{V} 3^{+}$epidermis-resident sIELs play an important role in protection of the skin against tumors (Girardi et al., 2001), regulation of local inflammatory responses (Girardi et al., 2002), and promotion of wound healing (Jameson et al., 2002), among others. The expression of CCR10 on the fetal thymic $\mathrm{V}_{\mathrm{Y}} 3^{+}$sIEL precursors suggests its role in directing their migration into the skin. However, an earlier report found no apparent sIEL defect in adult CCR10-knockout mice (Jiang et al., 2010). Using the CCR10-knockout/EGFP-knockin mice, we found that while the fetal thymic $\mathrm{VY} 3^{+}$sIEL precursors expressed high levels of CCR10, they downregulated CCR10 after seeding in the skin and expanding, suggesting that CCR10 is preferentially involved in migration of the $\mathrm{V}_{\mathrm{Y}} 3^{+} \mathrm{y} \delta \mathrm{T}$ cells but not their expansion in(to) the skin, which is mediated by cytokine/receptors such as IL-15 and CD122 (Kawai et al., 1998; De Creus et al., 2002). Indeed, the CCR10-deficient fetal thymic ${\mathrm{V} Y 3^{+}}^{+}$sIEL precursors are impaired in migration into the fetal skin, resulting in reduced numbers of sIELs in the newborn mice (Jin et al., 2010b). However, the impaired migration of the ${\mathrm{V} Y 3^{+}}^{+}$sIEL precursors is partially compensated for by their expansion in the skin with increased ages of mice. Therefore, given time, the fewer CCR10-deficient sIEL precursors that made it to the skin could expand efficiently to reach the level of the wild type mice. The CCR10-knockout $V_{\gamma} 3^{+} \mathrm{y} \delta \mathrm{T}$ cells also have improper morphology and altered epidermal vs dermal distribution within the skin of adult mice (Jin et al., 2010b). While mechanisms of the altered morphology and distribution of $\mathrm{V}_{\mathrm{Y}} 3^{+}$cells in the skin are not clear, they are likely associated with the regulated expression of CCR10 and other chemokine receptors. In the skin, while sIELs downregulate CCR10, they upregulate the expression of other chemokine receptors important for their maintenance in the skin such as CCR4, whose ligands CCL17 and CCL22 are highly expressed in the skin (Jiang et al., 2010). How the regulated downregulation of CCR10 on sIELs is involved in their proper maintenance in the skin is an interesting question.

Up to now, how expression of CCR10 affects migration and maintenance of the other thymic $\gamma \delta$ and NK T cell subsets during their development is not clear. The expression patterns of CCR10 and other homing molecules on these cells are consistent with the fact that many of these non-conventional $T$ cells preferentially localize into epithelial tissues and support the hypothesis that peripheral location and functions of these cells are pre-programmed in the thymus during their development processes (Tilloy et al., 1999; Hayday, 2000; Treiner et al., 2003; Yamagata et al., 2004; Staton et al., 2006; Jensen et al., 2009; Jin et al., 2010b).

\section{CCL28 as an antimicrobial protein}

Besides serving as a ligand for chemokine receptors CCR10 and CCR3, both human and mouse CCL28 were found to have broad-spectrum antimicrobial activities against various microorganisms such as Candida albicans, Gram-negative and -positive bacterial pathogens, and anaerobic periodontal pathogens Porphyromonas gingivalis and Actinobacillus actinomycetemcomitans (Hieshima et al., 2003; Watkins et al., 2007). The antimicrobial activity of CCL28 was reported to reside in its C-terminal region, which has a significant sequence similarity to histatin-5, a candidacidal peptide found in human saliva. It was also demonstrated that in the mouse CCL28, the C-terminal region containing a group of highly-charged amino acids is essential for its antimicrobial activity (Liu and Wilson, 2010). Like many other antimicrobial proteins, CCL28 exerted its antimicrobial activity in low-salt conditions of body fluids by disrupting the membrane integrity of target microbes (Hieshima et al., 2003). Consistent with its role in the antimicrobial activity, high levels of CCL28 are secreted by lactating mammary glands into milks and salivary glands into saliva. On the other hand, CCL27 does not have any notable antimicrobial activity.

\section{REGULATION OF EXPRESSION OF CCR10 AND ITS LIGANDS CCL27 AND CCL28}

Regulation of the CCR10 expression has been studied on thymic $\gamma \delta \mathrm{T}$ cells during their developmental processes and conventional $\alpha \beta T$ cells during their activation in epithelial tissue inflammation. In a study to assess how the TCR signaling is involved in expression of CCR10 in fetal thymic $\gamma \delta \mathrm{T}$ cells using two $\mathrm{V}_{\mathrm{Y}} 2^{+} \mathrm{y} \delta \mathrm{TCR}$ transgenic mice (Dent et al., 1990; Ishida et al., 1990; Ito et al., 1990), we found that the fetal thymic transgenic $\gamma \delta T$ cells upregulate the CCR10 expression only in mice with high expression of ligands for the transgenic $\gamma \delta$ TCRs, suggesting that a strong $\gamma \delta$ TCR signal is required for induction of CCR10 expression in fetal thymic y $\delta \mathrm{T}$ cells (Jin et al., 2010a). Interestingly, the high-affinity TCR/ligand interaction induced apoptosis (negative selection) of adult thymic T cells (Dent et al., 1990), suggesting that the fetal thymic $y \delta T$ cells are programmed to upregulate CCR10 in response to the high-affinity TCR selection. Supporting this, the fetal thymic transgenic $y \delta$ T cells had an "OPEN" CCR10 locus with a transcription-permissive configuration even before they express CCR10 (Jin et al., 2010a). 
While the transgenic $y \delta \mathrm{T}$ cell study provides strong evidence for requirement of TCR signals in upregulation of CCR10 on developing fetal thymic $y \delta T$ cells, it is still not clear what induces the CCR10 expression on the fetal thymic skin-bound $\mathrm{V}_{\mathrm{\gamma}} 3^{+}$cells since the ligand for $\mathrm{V}_{\mathrm{\gamma}} 3 \mathrm{TCR}$ is not known. In FVB (Taconic) mice in which the fetal thymic $\mathrm{V}_{\mathrm{\gamma}} 3^{+}$ $T$ cells could not undergo a positive selection due to mutation of Skint1 gene (Boyden et al., 2008), they still upregulate the CCR10 expression but differentiate into a different population with a homing molecule expression pattern similar to that of Vү3-negative $ү \delta \mathrm{T}$ cells and producing IL-17 (Jin et al., 2010a; Turchinovich and Hayday, 2011).

Except for the TCR signal, no other molecules are known to induce CCR10 on developing thymic T cells. It is not known either how the regulated expression of CCR10 is achieved in tissue-resident T cells of the skin or mucosa. Like upregulation of CCR10 in the positively selected fetal thymic $\mathrm{V} 3^{+}$sIEL precursors, its downregulation in $\mathrm{V} 3^{+}$sIELs is also programmed. Although remaining to be addressed, this downregulation is not due to a negative feedback mechanism associated with the CCR10/ligand interaction in the skin (Jin et al., 2010b). Instead, it might be a process associated with the intrinsic property and expansion, maintenance and function of sIELs in the skin.

In an in vitro study, 1,25-dihydroxy-vitamin D3 $\left[1,25(\mathrm{OH})_{2} \mathrm{D}_{3}\right]$, the active form of vitamin $\mathrm{D}$, has been found to enhance expression of CCR10 on human T cells isolated from blood (Sigmundsdottir et al., 2007). Interestingly, the dendritic cells isolated from skin-associated lymphoid tissues are found to express high levels of enzymes required for generation of $1,25(\mathrm{OH})_{2} \mathrm{D}_{3}$ from inactive forms of Vitamin $\mathrm{D}$ (Sigmundsdottir et al., 2007). 1,25( $(\mathrm{OH})_{2} \mathrm{D}_{3}$ also suppresses the retinoid acid-induced expression of gut-homing molecules CCR 9 and integrin $\alpha 4 \beta 7$ on the in vitro activated T cells. On the other hand, retinoid acid enhanced the $1,25(\mathrm{OH})_{2} \mathrm{D}_{3}$ induced upregulation of CCR10 (Sigmundsdottir et al., 2007). These findings are suggested to support the notion that antigen-presenting cells of specific tissues imprint $T$ cells to acquire homing properties towards the tissues where the antigen-presenting cells originate. However, considering that the CCR10 ligands are expressed in both skin and mucosal tissues, how the $1,25(\mathrm{OH})_{2} \mathrm{D}_{3}$-induced upregulation of CCR10 on $\mathrm{T}$ cells is associated with their specific epithelial tissue locations in vivo needs further studies.

The upregulation of CCR10 could also be induced on human $\lg \mathrm{A}^{+}$cells in vitro differentiated from naive $\mathrm{B}$ cells by retinoid acids and/or $1,25(\mathrm{OH})_{2} \mathrm{D}_{3}$ (Shirakawa et al., 2008). The induction of CCR10 on the human B cells is not necessarily associated with the $\lg A$ isotype switch, suggesting that upregulation of CCR10 and IgA isotype switch could be induced by distinctive signal pathways although the two events are usually associated in vivo. Notably, $1,25(\mathrm{OH})_{2} \mathrm{D}_{3}$ does not induce CCR10 expression on murine $\mathrm{T}$ and $\mathrm{B}$ cells in vitro, putatively due to absence of any vitamin $D$ response element in the promoter region of murine CCR10 gene (Sigmundsdottir et al., 2007; Shirakawa et al., 2008). How the CCR10 expression is induced on activated $\mathrm{T}$ and $\mathrm{B}$ cells in vivo during the skin and mucosal immune responses are not known.

Correlating with the induced upregulation of CCR10 on skin- or gut-homing $\mathrm{T}$ and $\lg \mathrm{A}^{+}$plasma cells for their involvement in immune activation in the local tissues, the skin or intestinal inflammation upregulates its ligands (Homey et al., 2002). In vitro, the upregulation of CCL27 could be induced on normal human keratinocytes by pro-inflammatory cytokines tumor necrosis factor- $\alpha$ (TNF- $\alpha$ ) and interleukin-1 $\beta$

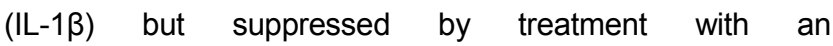
anti-inflammatory drug, glucocorticosteroid clobetasol propionate (Morales et al., 1999; Homey et al., 2002). Inhibiting activation of NF-kB or p38 mitogen-activated protein (MAP) kinase and their downstream pathways reduced the inflammatory cytokine-induced CCL27 expression, suggesting that both p38 MAPK and NF-KB signaling pathways are involved in the upregulation of CCL27 (Vestergaard et al., 2005; Riis et al., 2011b). The lipid mediator leukotriene B4 enhances the TNF-a-induced CCL27 expression in human keratinocytes while prostaglandin E2 suppresses it through modulating the NF-kB pathway.

Regulation of CCL28 was also studied in association with tissue inflammation. Although CCL28 is not highly expressed in the normal skin, it is upregulated in the skin of patients with psoriasis and atopic dermatitis (Wang et al., 2000; Kagami et al., 2005). Like CCL27, upregulation of CCL28 in human keratinocytes could be induced by IL- $1 \beta$ and TNF- $\alpha$ (Kagami et al., 2006). However, the downstream signal pathways regulating the CCL28 expression in keratinocytes might be different from those for CCL27. The CCL28 production was downregulated by inhibitors of extracellular signal-regulated kinase and NF-KB but not by inhibitors of p38 MAP kinase (Kagami et al., 2006). The upregulation of CCL28 is also observed in inflamed mucosal tissues, such as colons (Ogawa et al., 2004), duodenal mucosa (Maeda et al., 2011), ileum of Cohn's disease patients, lungs (John et al., 2005; Scanlon et al., 2011), and liver bile ducts (Eksteen et al., 2006). In a study of the CCL28 regulation in human colon epithelial cells, pro-inflammatory stimuli such as IL-1 and bacterial flagellin significantly upregulate CCL28 expression and the IL-1- or flagellin-stimulated CCL28 upregulation was synergistically increased by pretreatment with the short-chain fatty acid n-butyrate through modulation of the NF-KB signal pathway (Ogawa et al., 2004). In a study of the CCL28 upregulation in bile ducts, it was found that CCL28 was secreted by cholangiocytes (the epithelial cells of the bile duct) in response to LPS, IL-1 $\beta$, or bile acids (Eksteen et al., 2006). The enhanced levels of CCL28 could also be induced on human airway cells in vitro by IL-17A, another cytokine primarily involved in the inflammation. Treatments that reduced inflammation in ileum of Crohn's disease patients reduced the CCL28 expression, confirming that the CCL28 upregulation is 
induced by the tissue inflammation in vivo.

\section{INVOLVEMENT OF CCR10 AND ITS LIGANDS IN TUMOR PROGRESSION}

CCR10 and its ligands are expressed on various epithelia-homing or -originated cancer cells and might play an important role in their specific tissue location, survival and metastasis. Skin lesions of adult T-cell leukemia/lymphoma (ATLL) contained transcripts of CCR10 and its ligands CCL27 and CCL28, suggesting that CCR10/ligands play a role in the ATLL invasion into the skin. Consistent with this, cutaneous T-cell lymphoma such as mycosis fungoides has extensive expression of CCR10 (Notohamiprodjo et al., 2005; Fujita et al., 2006). Human malignant melanoma, a type of skin cancer of melanocytes, also has a high level of CCR10 expression that is associated with a lower survival rate and shorter time to progression (Müller et al., 2001; Kuhnelt-Leddihn et al., 2012). The CCR10 expression on melanoma cancer cells might promote their progression and immune escape (Simonetti et al., 2006). In mouse experiments, ectopically expressed CCR10 on melanoma cell lines increased their survival through engagement with locally produced CCL27, allowing the melanoma cells to escape host immune antitumor killing mechanisms, possibly by increasing the expression of anti-apoptotic molecules such as BCL-2 (Murakami et al., 2003). In squamous cell carcinoma, over-expression of CCR10 and CCL27 was associated with the tumor progression (Kai et al., 2011). Intriguingly, it was reported that some human keratinocyte-derived skin tumors might downregulate the expression of CCL27 to prevent attraction of the T cell-mediated antitumor immunity (Pivarcsi et al., 2007). On the other hand, ovarian cancer cells under hypoxia conditions upregulate expression of CCL28 to promote recruitment of CCR10-expressing regulatory $\mathrm{T}$ (Treg) cells for the tumor tolerance and angiogenesis (Facciabene et al., 2011).

\section{FUTURE DIRECTIONS}

While CCR10 is found involved in many aspects of the epithelial immunity, mechanisms underlying its expression in vivo are still poorly understood. Particularly, while several subsets of innate-like lymphocytes generated in the thymus are programmed to express CCR10 that might be important for their preferential epithelial localization, extracellular stimuli and intracellular signal pathways responsible for the programmed expression of CCR10 are unknown. Considering that those innate-like lymphocytes are preferentially generated in the fetal and neonatal stages, this likely involves unique intrinsic properties of fetal hematopoietic progenitor cells, which are known to have different developmental potentials than adult hematopoietic progenitors. During the functional phases in which $\mathrm{T}$ cells are recruited into the skin in response to the local inflammation, it is not clear when and where CCR10 is upregulated on various subsets of T cells. Furthermore, molecular events required for the CCR10 expression on $\mathrm{T}$ cells at the different functional phases (activating, resolving and memory) of $T$ cell responses in the skin are essentially unknown. Similarly, how CCR10 is upregulated and maintained on the mucosal IgA-producing cells in vivo is unclear either.

Relating with the regulation of CCR10 expression, in vivo functions of CCR10 in various subsets of T cells at different phases of immune responses in epithelial tissues such as the skin will be important questions. Past reports on the roles of CCR10 in different skin inflammation diseases seem inconsistent in some cases. Likely, this might reflect the diverse functions of CCR10/ligands on different $T$ cell subsets at different stages of their actions. Considering that CCR10 is expressed by different immune cell subsets, how CCR10/ ligands coordinate various immune cells in epithelial tissue immune responses will be another important question.

\section{REFERENCES}

Bowman, E.P., Kuklin, N.A., Youngman, K.R., Lazarus, N.H., Kunkel, E.J., Pan, J., Greenberg, H.B., and Butcher, E.C. (2002). The intestinal chemokine thymus-expressed chemokine (CCL25) attracts IgA antibody-secreting cells. J Exp Med 195, 269-275.

Boyden, L.M., Lewis, J.M., Barbee, S.D., Bas, A., Girardi, M., Hayday, A.C., Tigelaar, R.E., and Lifton, R.P. (2008). Skint1, the prototype of a newly identified immunoglobulin superfamily gene cluster, positively selects epidermal gammadelta T cells. Nat Genet 40, $656-662$.

Cerutti, A., and Rescigno, M. (2008). The biology of intestinal immunoglobulin A responses. Immunity 28, 740-750.

Cha, H.R., Ko, H.J., Kim, E.D., Chang, S.Y., Seo, S.U., Cuburu, N., Ryu, S., Kim, S., and Kweon, M.N. (2011). Mucosa-associated epithelial chemokine/CCL28 expression in the uterus attracts CCR10+ IgA plasma cells following mucosal vaccination via estrogen control. J Immunol 187, 3044-3052.

Charo, I.F., and Ransohoff, R.M. (2006). The many roles of chemokines and chemokine receptors in inflammation. $\mathrm{N}$ Engl $\mathrm{J}$ Med 354, 610-621.

Chen, L., Lin, S.X., Agha-Majzoub, R., Overbergh, L., Mathieu, C., and Chan, L.S. (2006). CCL27 is a critical factor for the development of atopic dermatitis in the keratin-14 IL-4 transgenic mouse model. Int Immunol 18, 1233-1242.

Corthésy, B. (2007). Roundtrip ticket for secretory lgA: role in mucosal homeostasis? J Immunol 178, 27-32.

De Creus, A., Van Beneden, K., Stevenaert, F., Debacker, V., Plum, J., and Leclercq, G. (2002). Developmental and functional defects of thymic and epidermal $\mathrm{V}$ gamma 3 cells in IL-15-deficient and IFN regulatory factor-1-deficient mice. J Immunol 168, 6486-6493.

Dent, A.L., Matis, L.A., Hooshmand, F., Widacki, S.M., Bluestone, J.A., and Hedrick, S.M. (1990). Self-reactive $y \delta T$ cells are eliminated in the thymus. Nature 343, 714-719.

Duhen, T., Geiger, R., Jarrossay, D., Lanzavecchia, A., and Sallusto, F. (2009). Production of interleukin 22 but not interleukin 17 by a 
subset of human skin-homing memory T cells. Nat Immunol 10, 857-863.

Eksteen, B., Miles, A., Curbishley, S.M., Tselepis, C., Grant, A.J., Walker, L.S., and Adams, D.H. (2006). Epithelial inflammation is associated with CCL28 production and the recruitment of regulatory T cells expressing CCR10. J Immunol 177, 593-603.

English, K., Brady, C., Corcoran, P., Cassidy, J.P., and Mahon, B.P. (2006). Inflammation of the respiratory tract is associated with CCL28 and CCR10 expression in a murine model of allergic asthma. Immunol Lett 103, 92-100.

Eyerich, S., Eyerich, K., Pennino, D., Carbone, T., Nasorri, F., Pallotta, S., Cianfarani, F., Odorisio, T., Traidl-Hoffmann, C., Behrendt, H., et al. (2009). Th22 cells represent a distinct human $\mathrm{T}$ cell subset involved in epidermal immunity and remodeling. $\mathrm{J}$ Clin Invest 119, 3573-3585.

Facciabene, A., Peng, X., Hagemann, I.S., Balint, K., Barchetti, A., Wang, L.P., Gimotty, P.A., Gilks, C.B., Lal, P., Zhang, L., et al. (2011). Tumour hypoxia promotes tolerance and angiogenesis via CCL28 and T(reg) cells. Nature 475, 226-230.

Feng, N., Jaimes, M.C., Lazarus, N.H., Monak, D., Zhang, C., Butcher, E.C., and Greenberg, H.B. (2006). Redundant role of chemokines CCL25/TECK and CCL28/MEC in IgA+ plasmablast recruitment to the intestinal lamina propria after rotavirus infection. J Immunol 176, 5749-5759.

Fujita, Y., Abe, R., Sasaki, M., Honda, A., Furuichi, M., Asano, Y., Norisugi, O., Shimizu, T., and Shimizu, H. (2006). Presence of circulating CCR10+ T cells and elevated serum CTACK/CCL27 in the early stage of mycosis fungoides. Clin Cancer Res 12, 2670-2675.

Girardi, M., Lewis, J., Glusac, E., Filler, R.B., Geng, L., Hayday, A.C., and Tigelaar, R.E. (2002). Resident skin-specific gammadelta $T$ cells provide local, nonredundant regulation of cutaneous inflammation. J Exp Med 195, 855-867.

Girardi, M., Oppenheim, D.E., Steele, C.R., Lewis, J.M., Glusac, E., Filler, R., Hobby, P., Sutton, B., Tigelaar, R.E., and Hayday, A.C. (2001). Regulation of cutaneous malignancy by gammadelta $T$ cells. Science 294, 605-609.

Grayson, M.H., Cheung, D., Rohlfing, M.M., Kitchens, R., Spiegel, D.E., Tucker, J., Battaile, J.T., Alevy, Y., Yan, L., Agapov, E., et al. (2007). Induction of high-affinity lgE receptor on lung dendritic cells during viral infection leads to mucous cell metaplasia. J Exp Med 204, 2759-2769.

Hayakawa, I., Hasegawa, M., Matsushita, T., Yanaba, K., Kodera, M., Komura, K., Takehara, K., and Sato, S. (2005). Increased cutaneous T-cell-attracting chemokine levels in sera from patients with systemic sclerosis. Rheumatology (Oxford) 44, 873-878.

Hayday, A.C. (2000). [gamma][delta] cells: a right time and a right place for a conserved third way of protection. Annu Rev Immunol 18, 975-1026.

Hieshima, K., Kawasaki, Y., Hanamoto, H., Nakayama, T., Nagakubo, D., Kanamaru, A., and Yoshie, O. (2004). CC chemokine ligands 25 and 28 play essential roles in intestinal extravasation of IgA antibody-secreting cells. J Immunol 173, 3668-3675.

Hieshima, K., Ohtani, H., Shibano, M., Izawa, D., Nakayama, T., Kawasaki, Y., Shiba, F., Shiota, M., Katou, F., Saito, T., et al. (2003). CCL28 has dual roles in mucosal immunity as a chemokine with broad-spectrum antimicrobial activity. J Immunol
170, 1452-1461.

Hijnen, D., De Bruin-Weller, M., Oosting, B., Lebre, C., De Jong, E., Bruijnzeel-Koomen, C., and Knol, E. (2004). Serum thymus and activation-regulated chemokine (TARC) and cutaneous T cell- attracting chemokine (CTACK) levels in allergic diseases: TARC and CTACK are disease-specific markers for atopic dermatitis. $J$ Allergy Clin Immunol 113, 334-340.

Homey, B., Alenius, H., Müller, A., Soto, H., Bowman, E.P., Yuan, W., McEvoy, L., Lauerma, A.I., Assmann, T., Bünemann, E., et al. (2002). CCL27-CCR10 interactions regulate T cell-mediated skin inflammation. Nat Med 8, 157-165.

Homey, B., Wang, W., Soto, H., Buchanan, M.E., Wiesenborn, A., Catron, D., Müller, A., McClanahan, T.K., Dieu-Nosjean, M.C., Orozco, R., et al. (2000). Cutting edge: the orphan chemokine receptor $\mathrm{G}$ protein-coupled receptor-2 (GPR-2, CCR10) binds the skin-associated chemokine CCL27 (CTACK/ALP/ILC). J Immunol 164, 3465-3470.

Hon, K.L., Leung, T.F., Ma, K.C., Li, A.M., Wong, Y., and Fok, T.F. (2004). Serum levels of cutaneous T-cell attracting chemokine (CTACK) as a laboratory marker of the severity of atopic dermatitis in children. Clin Exp Dermatol 29, 293-296.

Hu, S., Yang, K., Yang, J., Li, M., and Xiong, N. (2011). Critical roles of chemokine receptor CCR10 in regulating memory IgA responses in intestines. Proc Natl Acad Sci U S A 108, E1035-E1044.

Ishida, I., Verbeek, S., Bonneville, M., Itohara, S., Berns, A., and Tonegawa, S. (1990). T-cell receptor $\gamma \delta$ and $\gamma$ transgenic mice suggest a role of a $y$ gene silencer in the generation of $\alpha \beta$ T cells. Proc Natl Acad Sci U S A 87, 3067-3071.

Ito, K., Van Kaer, L., Bonneville, M., Hsu, S., Murphy, D.B., and Tonegawa, S. (1990). Recognition of the product of a novel MHC TL region gene $(27 \mathrm{~b})$ by a mouse gamma delta T cell receptor. Cell $62,549-561$.

Jameson, J., Ugarte, K., Chen, N., Yachi, P., Fuchs, E., Boismenu, R., and Havran, W.L. (2002). A role for skin gammadelta T cells in wound repair. Science 296, 747-749.

Jarmin, D.I., Rits, M., Bota, D., Gerard, N.P., Graham, G.J., Clark-Lewis, I., and Gerard, C. (2000). Cutting edge: identification of the orphan receptor G-protein-coupled receptor 2 as CCR10, a specific receptor for the chemokine ESkine. J Immunol 164, 3460-3464.

Jensen, K.D., Shin, S., and Chien, Y.H. (2009). Cutting edge: Gammadelta intraepithelial lymphocytes of the small intestine are not biased toward thymic antigens. J Immunol 182, 7348-7351.

Jiang, X., Campbell, J.J., and Kupper, T.S. (2010). Embryonic trafficking of gammadelta $T$ cells to skin is dependent on E/P selectin ligands and CCR4. Proc Natl Acad Sci U S A 107, 7443-7448.

Jin, Y., Xia, M., Saylor, C.M., Narayan, K., Kang, J., Wiest, D.L., Wang, Y., and Xiong, N. (2010a). Cutting edge: Intrinsic programming of thymic $Y \delta T$ cells for specific peripheral tissue localization. J Immunol 185, 7156-7160.

Jin, Y., Xia, M., Sun, A., Saylor, C.M., and Xiong, N. (2010b). CCR10 is important for the development of skin-specific gammadeltaT cells by regulating their migration and location. J Immunol 185, 5723-5731.

John, A.E., Thomas, M.S., Berlin, A.A., and Lukacs, N.W. (2005). Temporal production of CCL28 corresponds to eosinophil accu- 
mulation and airway hyperreactivity in allergic airway inflammation. Am J Pathol 166, 345-353.

Kagami, S., Kakinuma, T., Saeki, H., Tsunemi, Y., Fujita, H., Sasaki, K., Nakamura, K., Takekoshi, T., Kishimoto, M., Mitsui, H., et al. (2005). Increased serum CCL28 levels in patients with atopic dermatitis, psoriasis vulgaris and bullous pemphigoid. J Invest Dermatol 124, 1088-1090.

Kagami, S., Saeki, H., Komine, M., Kakinuma, T., Nakamura, K., Tsunemi, Y., Sasaki, K., Asahina, A., and Tamaki, K. (2006). CCL28 production in HaCaT cells was mediated by different signal pathways from CCL27. Exp Dermatol 15, 95-100.

Kagami, S., Saeki, H., Tsunemi, Y., Nakamura, K., Kuwano, Y., Komine, M., Nakayama, T., Yoshie, O., and Tamaki, K. (2008). CCL27-transgenic mice show enhanced contact hypersensitivity to Th2, but not Th1 stimuli. Eur J Immunol 38, 647-657.

Kai, H., Kadono, T., Kakinuma, T., Tomita, M., Ohmatsu, H., Asano, Y., Tada, Y., Sugaya, M., and Sato, S. (2011). CCR10 and CCL27 are overexpressed in cutaneous squamous cell carcinoma. Pathol Res Pract 207, 43-48.

Kakinuma, T., Saeki, H., Tsunemi, Y., Fujita, H., Asano, N., Mitsui, H., Tada, Y., Wakugawa, M., Watanabe, T., Torii, H., et al. (2003). Increased serum cutaneous T cell-attracting chemokine (CCL27) levels in patients with atopic dermatitis and psoriasis vulgaris. $J$ Allergy Clin Immunol 111, 592-597.

Kanda, N., Koike, S., and Watanabe, S. (2005). IL-17 suppresses TNF-alpha-induced CCL27 production through induction of COX-2 in human keratinocytes. J Allergy Clin Immunol 116, 1144-1150.

Kawai, K., Suzuki, H., Tomiyama, K., Minagawa, M., Mak, T.W., and Ohashi, P.S. (1998). Requirement of the IL-2 receptor beta chain for the development of Vgamma3 dendritic epidermal T cells. J Invest Dermatol 110, 961-965.

Kraynyak, K.A., Kutzler, M.A., Cisper, N.J., Khan, A.S., Draghia-Akli, R., Sardesal, N.Y., Lewis, M.G., Yan, J., and Weiner, D.B. (2010). Systemic immunization with CCL27/CTACK modulates immune responses at mucosal sites in mice and macaques. Vaccine 28 , 1942-1951.

Kuhnelt-Leddihn, L., Muller, H., Eisendle, K., Zelger, B., and Weinlich, G. (2012). Overexpression of the chemokine receptors CXCR4, CCR7, CCR9, and CCR10 in human primary cutaneous melanoma: a potential prognostic value for CCR7 and CCR10? Arch Dermatol Res 304,185-193.

Kunkel, E.J., Kim, C.H., Lazarus, N.H., Vierra, M.A., Soler, D., Bowman, E.P., and Butcher, E.C. (2003). CCR10 expression is a common feature of circulating and mucosal epithelial tissue IgA Ab-secreting cells. J Clin Invest 111, 1001-1010.

Lazarus, N.H., Kunkel, E.J., Johnston, B., Wilson, E., Youngman, K.R., and Butcher, E.C. (2003). A common mucosal chemokine (mucosae-associated epithelial chemokine/CCL28) selectively attracts IgA plasmablasts. J Immunol 170, 3799-3805.

Liu, B., and Wilson, E. (2010). The antimicrobial activity of CCL28 is dependent on C-terminal positively-charged amino acids. Eur $\mathrm{J}$ Immunol 40, 186-196.

Lorenz, R.G., Chaplin, D.D., McDonald, K.G., McDonough, J.S., and Newberry, R.D. (2003). Isolated lymphoid follicle formation is inducible and dependent upon lymphotoxin-sufficient B lymphocytes, lymphotoxin beta receptor, and TNF receptor I function. J
Immunol 170, 5475-5482.

Maeda, S., Ohno, K., Nakamura, K., Uchida, K., Nakashima, K., Fukushima, K., Tsukamoto, A., Goto-Koshino, Y., Fujino, Y., and Tsujimoto, H. (2011). Quantification of chemokine and chemokine receptor gene expression in duodenal mucosa of dogs with inflammatory bowel disease. Vet Immunol Immunopathol 144, 290-298.

Marchese, A., Docherty, J.M., Nguyen, T., Heiber, M., Cheng, R., Heng, H.H., Tsui, L.C., Shi, X., George, S.R., and O'Dowd, B.F. (1994). Cloning of human genes encoding novel $G$ protein-coupled receptors. Genomics 23, 609-618.

McDonald, K.G., and Newberry, R.D. (2007). Whole-mount techniques to evaluate subepithelial cellular populations in the adult mouse intestine. Biotechniques 43, 50, 52, 54 passim.

Mei, H.E., Yoshida, T., Sime, W., Hiepe, F., Thiele, K., Manz, R.A., Radbruch, A., and Dörner, T. (2009). Blood-borne human plasma cells in steady state are derived from mucosal immune responses. Blood 113, 2461-2469.

Mirshahpanah, P., Li, Y.Y., Burkhardt, N., Asadullah, K., and Zollner, T.M. (2008). CCR4 and CCR10 ligands play additive roles in mouse contact hypersensitivity. Exp Dermatol 17, 30-34.

Moed, H., Boorsma, D.M., Tensen, C.P., Flier, J., Jonker, M.J., Stoof, T.J., von Blomberg, B.M., Bruynzeel, D.P., Scheper, R.J., Rustemeyer, T., et al. (2004). Increased CCL27-CCR10 expression in allergic contact dermatitis: implications for local skin memory. J Pathol 204, 39-46.

Mora, J.R., and von Andrian, U.H. (2008). Differentiation and homing of IgA-secreting cells. Mucosal Immunol 1, 96-109.

Morales, J., Homey, B., Vicari, A.P., Hudak, S., Oldham, E., Hedrick, J., Orozco, R., Copeland, N.G., Jenkins, N.A., McEvoy, L.M., et al. (1999). CTACK, a skin-associated chemokine that preferentially attracts skin-homing memory T cells. Proc Natl Acad Sci U S A 96, 14470-14475.

Morteau, O., Gerard, C., Lu, B., Ghiran, S., Rits, M., Fujiwara, Y., Law, Y., Distelhorst, K., Nielsen, E.M., Hill, E.D., et al. (2008). An indispensable role for the chemokine receptor CCR10 in IgA antibody-secreting cell accumulation. J Immunol 181, 6309-6315.

Müller, A., Homey, B., Soto, H., Ge, N., Catron, D., Buchanan, M.E., McClanahan, T., Murphy, E., Yuan, W., Wagner, S.N., et al. (2001). Involvement of chemokine receptors in breast cancer metastasis. Nature 410, 50-56.

Murakami, T., Cardones, A.R., Finkelstein, S.E., Restifo, N.P., Klaunberg, B.A., Nestle, F.O., Castillo, S.S., Dennis, P.A., and Hwang, S.T. (2003). Immune evasion by murine melanoma mediated through CC chemokine receptor-10. J Exp Med 198, 1337-1347.

Notohamiprodjo, M., Segerer, S., Huss, R., Hildebrandt, B., Soler, D., Djafarzadeh, R., Buck, W., Nelson, P.J., and von Luettichau, I. (2005). CCR10 is expressed in cutaneous T-cell lymphoma. Int J Cancer 115, 641-647.

Ogawa, H., limura, M., Eckmann, L., and Kagnoff, M.F. (2004). Regulated production of the chemokine CCL28 in human colon epithelium. Am J Physiol Gastrointest Liver Physiol 287, G1062-G1069.

Pabst, O., Ohl, L., Wendland, M., Wurbel, M.A., Kremmer, E., Malissen, B., and Förster, R. (2004). Chemokine receptor CCR9 contributes to the localization of plasma cells to the small intestine. $J$ 
Exp Med 199, 411-416.

Pan, J., Kunkel, E.J., Gosslar, U., Lazarus, N., Langdon, P., Broadwell, K., Vierra, M.A., Genovese, M.C., Butcher, E.C., and Soler, D. (2000). A novel chemokine ligand for CCR10 and CCR3 expressed by epithelial cells in mucosal tissues. J Immunol 165 , 2943-2949.

Pivarcsi, A., Müller, A., Hippe, A., Rieker, J., van Lierop, A., Steinhoff, M., Seeliger, S., Kubitza, R., Pippirs, U., Meller, S., et al. (2007). Tumor immune escape by the loss of homeostatic chemokine expression. Proc Natl Acad Sci U S A 104, 19055-19060.

Rainone, V., Dubois, G., Temchura, V., Überla, K., Clivio, A., Nebuloni, M., Lauri, E., Trabattoni, D., Veas, F., and Clerici, M. (2011). CCL28 induces mucosal homing of HIV-1-specific IgA-secreting plasma cells in mice immunized with HIV-1 virus-like particles. PLoS One 6, e26979.

Reiss, Y., Proudfoot, A.E., Power, C.A., Campbell, J.J., and Butcher, E.C. (2001). CC chemokine receptor (CCR)4 and the CCR10 ligand cutaneous $\mathrm{T}$ cell-attracting chemokine (CTACK) in lymphocyte trafficking to inflamed skin. J Exp Med 194, 1541-1547.

Riis, J.L., Johansen, C., Vestergaard, C., Bech, R., Kragballe, K., and Iversen, L. (2011a). Kinetics and differential expression of the skin-related chemokines CCL27 and CCL17 in psoriasis, atopic dermatitis and allergic contact dermatitis. Exp Dermatol 20, 789-794.

Riis, J.L., Johansen, C., Vestergaard, C., Otkjaer, K., Kragballe, K., and Iversen, L. (2011b). CCL27 expression is regulated by both p38 MAPK and IKKß signalling pathways. Cytokine 56, 699-707.

Scanlon, K.M., Hawksworth, R.J., Lane, S.J., and Mahon, B.P. (2011). IL-17A induces CCL28, supporting the chemotaxis of IgE-secreting B cells. Int Arch Allergy Immunol 156, 51-61.

Shirakawa, A.K., Nagakubo, D., Hieshima, K., Nakayama, T., Jin, Z., and Yoshie, O. (2008). 1,25-dihydroxyvitamin D3 induces CCR10 expression in terminally differentiating human B cells. J Immunol 180, 2786-2795.

Sigmundsdottir, H., Pan, J., Debes, G.F., Alt, C., Habtezion, A., Soler, D., and Butcher, E.C. (2007). DCs metabolize sunlight-induced vitamin D3 to 'program' $T$ cell attraction to the epidermal chemokine CCL27. Nat Immunol 8, 285-293.

Simonetti, O., Goteri, G., Lucarini, G., Filosa, A., Pieramici, T., Rubini, C., Biagini, G., and Offidani, A. (2006). Potential role of CCL27 and CCR10 expression in melanoma progression and immune escape. Eur J Cancer 42, 1181-1187.

Sisirak, V., Vey, N., Vanbervliet, B., Duhen, T., Puisieux, I., Homey, B., Bowman, E.P., Trinchieri, G., Dubois, B., Kaiserlian, D., et al. (2011). CCR6/CCR10-mediated plasmacytoid dendritic cell recruitment to inflamed epithelia after instruction in lymphoid tissues. Blood 118, 5130-5140.

Soler, D., Humphreys, T.L., Spinola, S.M., and Campbell, J.J. (2003). CCR4 versus CCR10 in human cutaneous TH lymphocyte trafficking. Blood 101, 1677-1682.

Song, T.W., Sohn, M.H., Kim, E.S., Kim, K.W., and Kim, K.E. (2006). Increased serum thymus and activation-regulated chemokine and cutaneous $T$ cell-attracting chemokine levels in children with atopic dermatitis. Clin Exp Allergy 36, 346-351.

Staton, T.L., Habtezion, A., Winslow, M.M., Sato, T., Love, P.E., and Butcher, E.C. (2006). CD8+ recent thymic emigrants home to and efficiently repopulate the small intestine epithelium. Nat Immunol 7 , 482-488.

Sundström, P., Lundin, S.B., Nilsson, L.A., and Quiding-Järbrink, M. (2008). Human IgA-secreting cells induced by intestinal, but not systemic, immunization respond to CCL25 (TECK) and CCL28 (MEC). Eur J Immunol 38, 3327-3338.

Suzuki, K., and Fagarasan, S. (2009). Diverse regulatory pathways for IgA synthesis in the gut. Mucosal Immunol 2, 468-471.

Tilloy, F., Treiner, E., Park, S.H., Garcia, C., Lemonnier, F., de la Salle, H., Bendelac, A., Bonneville, M., and Lantz, O. (1999). An invariant $T$ cell receptor alpha chain defines a novel TAP-independent major histocompatibility complex class lb-restricted alpha/beta T cell subpopulation in mammals. J Exp Med 189, 1907-1921.

Treiner, E., Duban, L., Bahram, S., Radosavljevic, M., Wanner, V., Tilloy, F., Affaticati, P., Gilfillan, S., and Lantz, O. (2003). Selection of evolutionarily conserved mucosal-associated invariant $T$ cells by MR1. Nature 422, 164-169.

Trifari, S., Kaplan, C.D., Tran, E.H., Crellin, N.K., and Spits, H. (2009). Identification of a human helper $\mathrm{T}$ cell population that has abundant production of interleukin 22 and is distinct from $\mathrm{T}(\mathrm{H})-17$, $\mathrm{T}(\mathrm{H}) 1$ and $\mathrm{T}(\mathrm{H}) 2$ cells. Nat Immunol 10, 864-871.

Tubo, N.J., McLachlan, J.B., and Campbell, J.J. (2011). Chemokine receptor requirements for epidermal T-cell trafficking. Am J Pathol 178, 2496-2503.

Turchinovich, G., and Hayday, A.C. (2011). Skint-1 identifies a common molecular mechanism for the development of interferon- $\gamma$-secreting versus interleukin-17-secreting $y \delta T$ cells. Immunity 35, 59-68.

Vestergaard, C., Deleuran, M., Gesser, B., and Grønhøj Larsen, C. (2003). Expression of the T-helper 2-specific chemokine receptor CCR4 on CCR10-positive lymphocytes in atopic dermatitis skin but not in psoriasis skin. Br J Dermatol 149, 457-463.

Vestergaard, C., Johansen, C., Otkjaer, K., Deleuran, M., and Iversen, L. (2005). Tumor necrosis factor-alpha-induced CTACK/CCL27 (cutaneous T-cell-attracting chemokine) production in keratinocytes is controlled by nuclear factor kappaB. Cytokine 29, 49-55.

Wang, W., Soto, H., Oldham, E.R., Buchanan, M.E., Homey, B., Catron, D., Jenkins, N., Copeland, N.G., Gilbert, D.J., Nguyen, N., et al. (2000). Identification of a novel chemokine (CCL28), which binds CCR10 (GPR2). J Biol Chem 275, 22313-22323.

Watkins, H.R., Lapp, C.A., Hanes, P.J., Dickinson, D.P., Volkmann, K.R., Newman, C.L., and Konzelman, J.L. (2007). CCL28 effects on periodontal pathogens. J Periodontol 78, 2356-2363.

Wilson, E., and Butcher, E.C. (2004). CCL28 controls immunoglobulin (Ig)A plasma cell accumulation in the lactating mammary gland and IgA antibody transfer to the neonate. J Exp Med 200, 805-809.

Xiong, N., Kang, C., and Raulet, D.H. (2004). Positive selection of dendritic epidermal gammadelta $\mathrm{T}$ cell precursors in the fetal thymus determines expression of skin-homing receptors. Immunity $21,121-131$.

Yamagata, T., Mathis, D., and Benoist, C. (2004). Self-reactivity in thymic double-positive cells commits cells to a CD8 alpha alpha lineage with characteristics of innate immune cells. Nat Immunol 5, 597-605. 